\title{
A LÓGICA DE LEWIS CARROLL NO ENSINO MÉDIO: UNIDADE DIDÁTICA E RELATO DE EXPERIÊNCIA
}

\author{
LEWIS CARROLL'S LOGIC IN HIGH SCHOOL: DIDACTIC UNIT AND EXPERIENCE \\ REPORT
}

John Lennon Lindemann'

\begin{abstract}
Resumo: $O$ presente trabalho consiste na apresentação de uma unidade didática para o ensino médio sobre a lógica silogística carrolliana, acompanhada do relato de sua aplicação e da avaliação de seus resultados. A unidade didática foi aplicada em uma turma do segundo ano do ensino médio. A motivação de sua realização foi a limitação dos métodos de ensino de lógica disponíveis no mercado editorial brasileiro. Os passos didáticos foram baseados em Gallo (2012). A avaliação dos resultados foi positiva, demonstrando que a lógica silogística de Carroll (1886) pode ser usada como um valioso instrumento para o ensino de lógica no ensino médio.
\end{abstract}

Palavras-chave: Ensino de lógica; Ensino Médio; Silogística carrolliana.

\begin{abstract}
The present work consists in the presentation of a didactic unit for high school on the Carrollian syllogistic logic, accompanied by the report of its application and the evaluation of its results. The didactic unit was applied in a class of the second year of high school. The reason for its accomplishment was the limitation of the methods of logic teaching available in the Brazilian publishing market. The didactic steps were based on Gallo (2012). The evaluation of the results was positive, demonstrating that Carroll's (1886) syllogistic logic can be used as a valuable instrument for teaching logic in the high school.
\end{abstract}

Keywords: Logic teaching; High school; Carrollian silogistics.

\section{INTRODUÇÃO}

O presente trabalho consiste na apresentação de uma unidade didática para o ensino médio sobre a lógica silogística carrolliana, acompanhada do relato de sua aplicação e do exame de seus resultados. O objetivo aqui não é apresentar a teoria silogística carrolliana como recurso 
didático para o ensino de lógica no ensino médio, o que já foi feito em Lindemann (2017), mas, dando continuidade a tal proposta, explorar sua aplicabilidade.

Lewis Carroll, pseudônimo de Charles Lutwidge Dodgson (1832-1898), é amplamente reconhecido pela divulgação e popularização da lógica em ambientes não acadêmicos, especialmente por suas obras literárias, consideradas romances matemáticos, isto é, uma literatura que desenvolve o raciocínio lógico e matemático do leitor (MONTOITO, 201 1, p. 9). Além de contribuir para a divulgação da lógica, Carroll também trabalhou para melhorar a qualidade de seu ensino, como percebemos em The Game of Logic (CARROLL, 1886), obra na qual o autor apresenta o seu método diagramático para a resolução de silogismos como um divertido jogo de peças, possibilitando o seu ensino de forma lúdica.

Dada a utilidade da lógica para a análise de argumentos e o reconhecimento de falácias, equipar os alunos com um ferramental lógico constitui uma etapa valiosa no processo de aprimoramento da autonomia intelectual e do pensamento crítico do educando, duas das finalidades do ensino médio (BRASIL, 2006, p. 28)2. Apesar de sua importância, a lógica ainda é apresentada como um subtema nos livros didáticos brasileiros de Filosofia (SECCO; PUGLIESE, 2016), causando dificuldades para o seu ensino.

O diagnóstico das limitações dos métodos de ensino de lógica nos livros didáticos disponíveis, somado à adequação da lógica silogística carrolliana ao ensino das sugestões do conteúdo de lógica das Orientações Curriculares para o Ensino Médio (BRASIL, 2006), foram, em síntese, as motivações que levaram a realização do trabalho cujo presente artigo é um fruto. As Orientações (BRASIL, 2006, p. 34) sugerem o ensino de lógica na proposta de conteúdo 2 (validade e verdade; proposição e argumento), 3 (reconhecimento de argumentos; conteúdo e forma) e 4 (quadro de oposições entre proposições categóricas; inferências imediatas em contexto categórico; conteúdo existencial e proposições categóricas).

O presente artigo está dividido em três seções, a primeira apresenta a escola e um breve perfil dos alunos, a segunda apresenta a unidade didática por meio do planejamento das aulas e a terceira apresenta o relato da experiência e o exame dos resultados obtidos.

\section{BREVE CONTEXTO: O CENÁRIO DA PRÁTICA}

O Colégio Nossa Senhora Medianeira foi fundado em 1950 e tem como mantenedora a Ação Social Diocesana de Santa Cruz do Sul, estando localizado no bairro central de Candelária, município do estado do Rio Grande do Sul com pouco mais de trinta mil habitantes. Segundo o seu atual regimento:

O Colégio Nossa Senhora Medianeira tem como missão promover a formação integral do indivíduo, incentivando-o ao desenvolvimento contínuo para uma atuação transformadora e comprometida com princípios éticos. Como Estabelecimento de Ensino, promove uma boa convivência aos educandos, proporcionando a formação de sujeitos autônomos, em que o principal conteúdo é o Ser Humano. (COLÉGIO NOSSA SENHORA MEDIANEIRA, 2017, p. 4)

2 A autonomia intelectual e o pensamento crítico do educando também são finalidades enfatizadas pela nova BNCC para o Ensino Médio, aprovada em dezembro de 2018 (BRASIL, 2018, p. 2). 
O colégio dispõe de um amplo espaço físico e o tamanho das salas de aula são adequados ao contingente de alunos. O colégio também oferece uma gama de recursos didáticos, como, por exemplo, a presença de um data show fixo na sala de aula do segundo ano do ensino médio, onde o presente trabalho foi realizado.

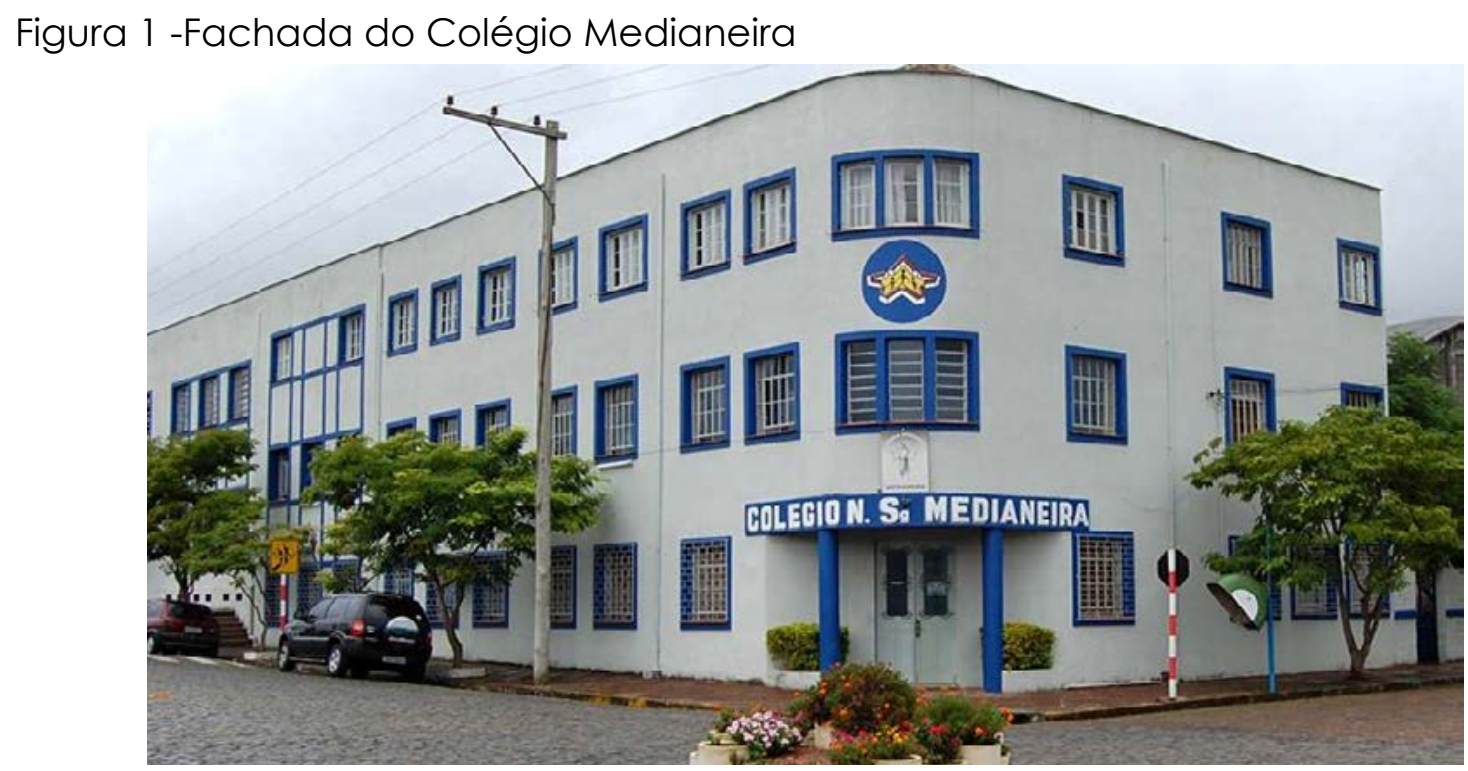

Fonte: Fotografia de Alíria Anton em 2018.

Além dos recursos materiais disponíveis, cabe salientar que o constante incentivo por parte da equipe diretiva para que o corpo docente busque novas e melhores metodologias didáticas foi a pedra angular para a construção deste trabalho.

O segundo ano do ensino médio de 2018 foi composto por 31 alunos, sendo 13 do sexo feminino e 18 do sexo masculino. As idades variaram entre 16 e 17 anos. Todos estavam cursando pela primeira vez o segundo ano.

Cada período de aula dura 50 minutos, sendo reservado um período por semana para a Filosofia.

\section{UNIDADE DIDÁTICA: A LÓGICA SILOGÍSTICA CARROLLIANA}

A presente unidade didática foi concebida aos moldes da proposta de Lindemann (2017), utilizando a obra The Game of Logic (CARROLL, 1886) como recurso auxiliar.

A estrutura didática da unidade foi livremente inspirada na metodologia proposta por Gallo (2012), que sugere quatro passos didáticos para o ensino de Filosofia: (1) sensibilização, onde se apresenta um tema aos educandos; (2) problematização, avançando em questões de cunho filosófico sobre o tema apresentado; (3) investigação, apresentando teorias filosóficas que auxiliem a pensar o tema problematizado e (4) conceituação, onde se promove o pensamento autônomo dos educandos sobre o tema, agora fundamentado pelos passos anteriores. Cabe especificar que os quatro passos didáticos estão divididos ao longo de todas as aulas da unidade.

As competências propostas ao educando foram elaboradas como o domínio prático de um tipo de tarefa e situação, aos moldes da noção de competência de Perrenoud e Magne (1999), enquanto os conteúdos almejados foram agrupados pela proposta de Coll e Martín (2004).

Segue-se a unidade didática, apresentada por meio de seus planos de aula: 
2.2 Disciplina: Filosofia

2.3 Docente: Prof. Me. John Lennon Lindemann

2.4 Turma: Segundo ano do ensino médio (2018)

2.5 Tempo de duração: 8 períodos (8 semanas)

2.6 Recursos utilizados: Quadro, giz e impressões.

2.7 Competências propostas ao educando:

- Compreender a noção de argumento; reconhecendo proposições, premissas e conclusão.

- Compreender a distinção entre argumentos dedutivos e indutivos.

- Conhecer as propriedades de argumentos dedutivos; diferenciando conteúdo e forma lógica, verdade e validade.

- Identificar as especificidades da argumentação silogística.

- Dominar o método diagramático para a resolução de silogismos carrolliano; usando-o para extrair conclusões, reconhecer argumentos válidos e identificar falácias.

2.8 Conteúdos almejados:

- Atitudinal: Desenvolver e analisar argumentos.

- Conceitual: Conhecer noções lógicas em geral, especialmente da silogística.

- Procedimental: Dominar o uso do método diagramático carrolliano para a resolução de silogismos.

2.9 Sequência de atividades:

AULA 1: Sensibilização e noções básicas

Apresentar falácias engraçadas para despertar o interesse em lógica nos alunos, tais como: "Vocês sabem que o queijo suíço tem furos? Quanto mais queijo, mais furos. Mas quanto mais furos, menos queijo. Logo, quanto mais queijo, menos queijo" e "Todos os gatos têm quatro patas. Meu cachorro tem quatro patas. Logo, meu cachorro é um gato.". Após a sensibilização, iniciar a problematização expondo o caráter falacioso dos argumentos apresentados e introduzindo noções básicas de argumentação, distinguindo premissas e conclusão, assim como a diferença entre argumentos dedutivos e indutivos. Encerrar com uma curta lista de argumentos, propondo aos alunos o exercício de identificar quais são dedutivos e quais são indutivos.

AULA 2: As propriedades dos argumentos dedutivos

Corrigir o exercício da última aula, relembrando as noções apresentadas. Continuar a problematização expondo a diferença entre verdade e validade, enfatizando que a lógica não se preocupa com o conteúdo da argumentação, mas apenas com a sua forma, exemplificando com argumentos válidos cujas premissas e conclusões são falsas. Encerrar propondo que os alunos pesquisem sobre a relação entre Aristóteles e a lógica.

\section{AULA 3: A lógica silogística carrolliana}

Relembrar as noções apresentadas e sugerir que alguns alunos compartilhem o resultado de suas pesquisas sobre Aristóteles, ajudando-os a enfatizar sua primazia no estudo sistemático da lógica. Apresentar a lógica silogística como uma teoria cujo conhecimento gera maior destreza lógica, sugerindo a investigação da teoria silogística carrolliana. Iniciar a investigação apresentando as noções básicas da silogística carrolliana: Proposições categóricas em Forma normal, Universo do Discurso, termos negativos e classes codivisionais. 
AULA 4: A representação diagramática

Apresentar os diagramas Triliteral e Biliteral, relembrando noções previamente apresentadas com o auxilio de suas respectivas representações diagramáticas. Propor exercícios de representação diagramática, auxiliando-os com suas dúvidas e aumentando paulatinamente o nível de dificuldade dos exercícios. Encerrar distribuindo impressões de um texto (Figura 2) que especifica todas as regras do método diagramático carrolliano, propondo que leiam e tentem utilizá-lo nos exercícios extra aula.

AULA 5: O método diagramático de resolução de silogismos

Expor o método diagramático de resolução de silogismos fazendo referência ao texto distribuído, com ênfase às regras que determinam o raciocínio visual pelo qual se infere os marcadores no diagrama Biliteral. Propor exercícios de resolução de silogismos pelo método diagramático, auxiliando-os e tirando dúvidas. Encerrar com mais exercícios como tarefa para a próxima aula.

\section{AULA 6: Exercícios}

Corrigir os exercícios deixados como tarefa extra aula e propor uma nova lista de exercícios como tarefa em aula, tirando as últimas dúvidas. Corrigir os exercícios e marcar uma prova para a próxima aula.

\section{AULA 7: Avaliação}

Aplicar uma prova individual com consulta, inclusive deixando que consultem o texto distribuído, buscando avaliar a capacidade de diagnosticarem a validade de silogismos usando o método diagramático e não o quanto decoraram suas regras.

Figura 2 -As regras do método diagramático carrolliano

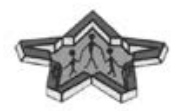

\section{COLÉGIO NOSSA SENHORA MEDIANEIRA}

As Regras do Método Diagramático Carrolliano

1. Definir o Universo do Discurso.

2. Identificar o termo médio nas premissas.

3. Traduzir as premissas para proposições em Forma normal com os termos em forma abstrata, sempre atento à possível ocorrência de termos negativos.

4. Caso alguma premissa seja uma proposição categórica Universal Afirmativa, então deve ser traduzida para a dupla de proposições correspondente, conforme a seguinte tabela:

\begin{tabular}{|c|c|c|}
\hline & Universal Afirmativa & Dupla de Proposições \\
\hline & "Todo $\Psi$ é $\Phi "$ & “Algum $\Psi$ é $\Phi ”$ e “Nenhum $\Psi$ é $\Phi ”$ \\
\hline & “Todo $\Psi$ é $\Phi^{\prime} "$ & “Algum $\Psi$ é $\Phi "$ e “Nenhum $\Psi$ é $\Phi "$ \\
\hline & “Todo $\Psi$ é Ф” & “Algum $\Psi$ 'é Ф” e “Nenhum $\Psi$ 'é $\Phi "$ \\
\hline & “Todo $\Psi$ é $\Phi "$ & “Algum $\Psi^{\prime}$ é $\Phi^{\prime} "$ e “Nenhum $\Psi$ ' é $\Phi "$ \\
\hline & \multicolumn{2}{|c|}{$\begin{array}{l}\text { Representar o conteúdo das premissas no diagrama Triliteral usando contadores: Primeiro deve- } \\
\text { se representar cada proposição Universal Negativa usando dois contadores vazios sobre as duas } \\
\text { células que associam os seus termos, depois deve-se representar cada proposição Particular } \\
\text { usando um contador de existência sobre a linha que divide as duas células que associam os seus } \\
\text { termos -mas se uma das células já estiver ocupada por um contador vazio em virtude da } \\
\text { representação prévia de uma Universal Negativa, então deve-se mover o contador de existência } \\
\text { para os limites da célula restante. }\end{array}$} \\
\hline \\
\hline \multicolumn{3}{|c|}{$\begin{array}{l}\text { Traduzir o conteúdo representado no diagrama Biliteral para proposições em Forma normal } \\
\text { com os termos em forma abstrata. }\end{array}$} \\
\hline \multicolumn{3}{|c|}{$\begin{array}{l}\text { Traduzir as proposiçōes em Forma normal oriundas do diagrama Biliteral para a linguagem } \\
\text { natural, sempre atento às limitações semânticas do Universo do Discurso. }\end{array}$} \\
\hline
\end{tabular}

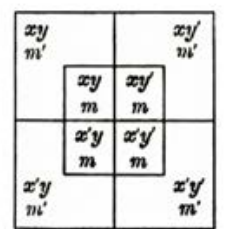

Diagrama Triliteral

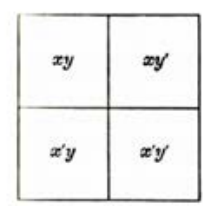

Diagrama Biliteral

Fonte: Elaborada pelo autor. 


\begin{abstract}
AULA 8: Conceituação
Apresentar a resolução de todos os silogismos da prova, esclarecendo dúvidas remanescentes. Encerrada a investigação, fomentar uma conceitualização, discutindo a importância e a utilidade da lógica, buscando esclarecer que ela não se limita à sistematização das regras que conduzem ao pensamento correto, mas também consiste em um instrumento útil na detecção de falácias, evitando que sejamos enganados, citando Carroll (1886, p. 32-33):
\end{abstract}

Você acredita que o uso principal da Lógica, na vida real, é deduzir conclusões a partir de premissas viáveis, e para convencer-se que as conclusões, deduzidas por outras pessoas, estão corretas, não é mesmo? Quisera que fosse assim! A sociedade estaria muito menos sujeita a pânico e outros delírios, e a vida política, especialmente, seria mesmo algo totalmente diferente, se a maioria dos argumentos transmitidos e espalhados pelo mundo fossem corretos! Mas receio que é exatamente o contrário. [...].

O uso principal que você fará da destreza lógica [...] será detectar 'falácias' $[\ldots]^{3}$

\title{
3. RELATO E EXAME DA EXPERIÊNCIA
}

A sequência de oito aulas começou no dia oito de outubro e encerrou no dia vinte e seis de novembro de 2018, exatamente entre o primeiro e o segundo turno das eleições presidenciais, inclusive com uma parte significativa dos alunos votando pela primeira vez. Prima facie, o melhor modo de sensibilizar os alunos seria apresentar argumentos polêmicos ou oriundos do cenário político atual, mas temi que a atenção dos alunos se voltaria apenas para o conteúdo dos argumentos e não para a sua forma lógica, por isso iniciei com uma abordagem diferente, apresentando falácias com apelo ao humor4.

Obviamente tal abordagem não tem a mesma potência sensibilizadora dos argumentos polêmicos ou oriundos do cenário político, mas acredito que cumpre melhor com sua finalidade. Embora alguns alunos tenham ficado apáticos no início, outros logo demonstraram empolgação com o tema, talvez fruto de seus interesses pessoais relativos à computação e programação.

O desenvolvimento das aulas seguiu tranquilo, sempre recebendo um feedback negativo ao questionar se possuíam qualquer dúvida. Esse cenário só mudou na quarta aula, com a introdução dos exercícios: embora tenham afirmado que compreenderam todas as regras, muitos tiveram dificuldade para as colocar em prática.

Diferente de algumas teorias filosóficas, aprender uma teoria lógica não se limita ao aprendizado de um conhecimento puramente teórico, mas inclúi o aprendizado de uma técnica, possuindo um domínio prático relativo à proficiência de um fazer, cujas dificuldades só emergem a partir da própria prática. Daí a necessidade de exercícios assistidos em sala de aula, através dos quais o professor pode esclarecer dúvidas com especificidades que são difíceis de prever.

A dicotomia entre o domínio teórico e prático no processo de ensino e aprendizagem de uma teoria lógica retém semelhança com os conceitos medievais de logica docens e logica utens usados pelos escolásticos, que derivaram o termo "utens" da palavra latina "uti", isto é,

3 Tradução de Frank Thomas Sautter; circulação privada.

4 A escolha de tal abordagem foi profundamente influenciada por conselhos recebidos nas disciplinas ministradas pelo Prof. Frank Sautter que cursei ao longo de minha formação, sendo oriundos das análises de sua vasta experiência com o ensino de lógica. 
"usar". Segundo Newton (2008, p. 223), o termo logica docens refere-se à lógica pura ou científica, enquanto logica utens refere-se ao seu uso em processos de tomada de decisão. Sob tais parâmetros, Engel (2006) defende um maior interesse no ensino da logica utens, focando o aprendizado vivo do espírito crítico, em detrimento da logica docens, limitada à transmissão de regras e preceitos.

Dada a importância da logica utens, cabe enfatizar que o método diagramático carrolliano mostrou-se incrivelmente adequado ao processo de ensino e aprendizado do domínio prático da lógica na medida em que possibilita que exercícios mais simples sejam feitos, como representar o conteúdo de uma única proposição no diagrama Biliteral, possibilitando que dúvidas mais básicas sejam sanadas antes da introdução de exercícios mais complexos, como representar o conteúdo de duas premissas Universais Afirmativas no diagrama Triliteral5. Carroll (1986, p. 37-96) fornece uma gama de exercícios úteis neste processo, dos mais básicos até os mais complexos.

Um aspecto interessante da relação de ensino e aprendizagem do domínio prático da lógica foi perceber que compreensões errôneas de noções teóricas foram sendo elucidadas pela compreensão de suas aplicações, como a relação entre o conteúdo existencial de uma proposição Universal Afirmativa e sua dupla de proposições correspondentes, cuja compreensão equivocada foi esclarecida pela representação diagramática do conteúdo das proposições.

Em relação à avaliação, optei por criar exercícios originais para evitar que algum aluno, caso houvesse pesquisado na Internet, já houvesse entrado em contato com o exercício. A prova consistiu em doze pares de premissas, desafiando-os a encontrar uma conclusão válida ou diagnosticar que qualquer possível conclusão seria inválida por meio da aplicação do método diagramático carrolliano.

Apenas dois alunos acertaram todos os exercícios, mas cinco erraram apenas um e a grande maioria atingiu notas acima da média. Seis alunos reprovaram e terão direito a uma nova avaliação.

Em relação aos exercícios da prova, conforme imagem abaixo, a maioria resultou em uma média de acertos similar, com exceção dos de número 1, 3, 6 e 12, cuja quantia de erros foi notável. $O$ par de premissas de tais exercícios se destaca dos demais por não possibilitar nenhuma conclusão válida.

Acredito que a quantia maior de erros foi resultado de um certo esquema de pensamento prévio dos alunos, que operaram como se todo exercício precisasse de uma resposta, mas sem aceitar que o fato de não haver uma resposta pode ser a solução correta. Em futuras aplicações da mesma unidade didática, além de dar mais ênfase ao fato de que certos conjuntos de premissas não possibilitam nenhuma conclusão válida, também pretendo propor uma atividade transdisciplinar com a disciplina de Matemática, associando premissas que não permitem inferir uma conclusão válida com sistemas de equação que não têm solução.

Sobre o término da unidade, o momento de conceituação foi muito frutífero. Se inicialmente eu evitei o uso de argumentos oriundos do cenário político atual, agora os próprios alunos apontaram a importância da lógica no processo de análise das propostas dos candidatos, também enfatizando a utilidade da lógica na detecção de fake news.

Figura 3 -Prova aplicada

5 Duas premissas Universais Negativas devem ser representadas no diagrama Triliteral por meio da representação de outras quatro proposições que juntas expressam o mesmo conteúdo existencial das premissas. 


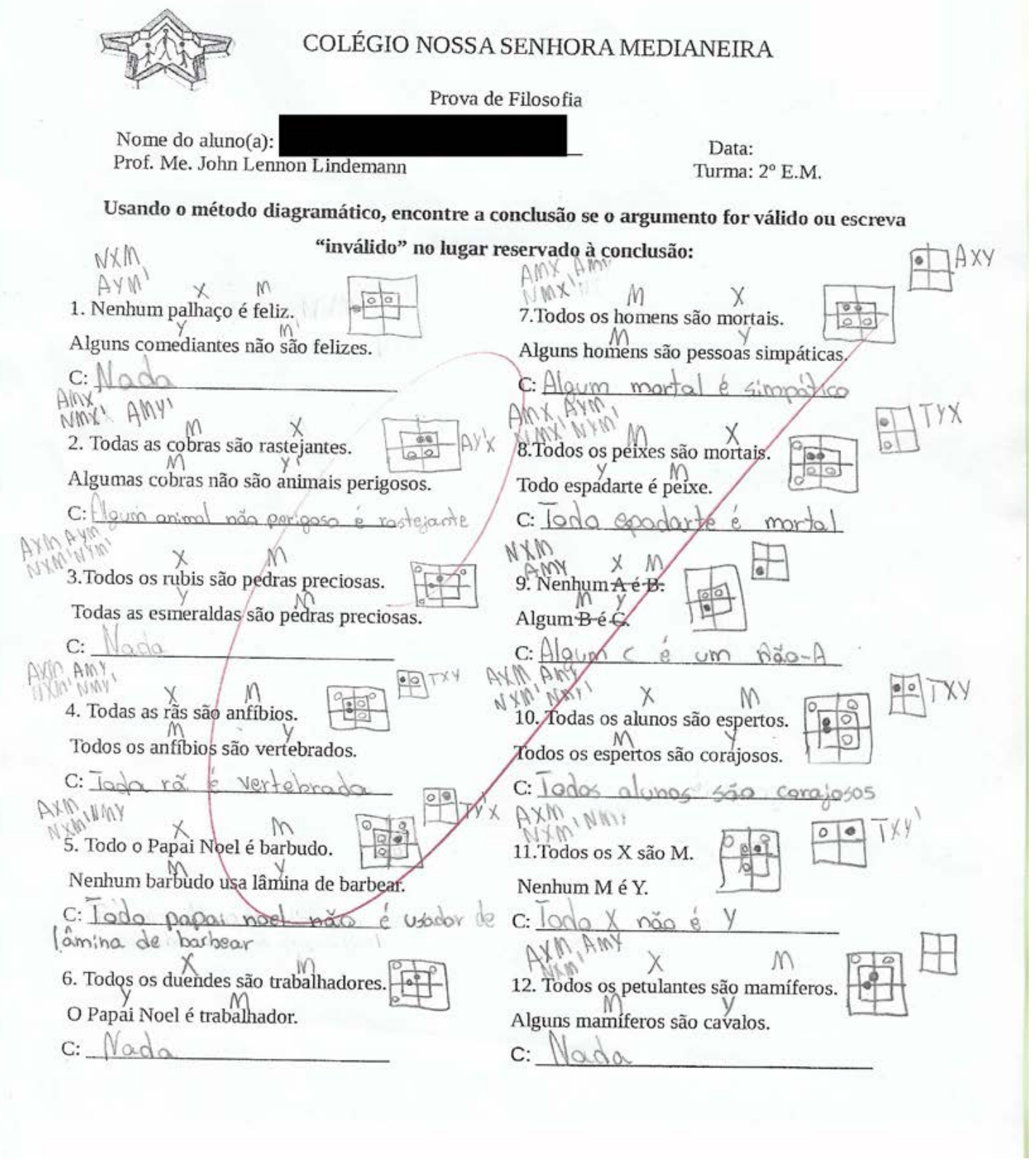

Na aula seguinte expus aos alunos o interesse em escrever um artigo sobre nossa experiência e pedi que escrevessem bilhetes anônimos com uma avaliação sincera sobre o método. Seguem alguns resultados:

Com o método de ensinamento proposto pelo professor, consegui absorver ao máximo todo o conteúdo em relação ao silogismo. Depois de prestar atenção nas aulas e concluir os exercícios, não necessitei reforçar o conteúdo em casa para concluir a prova.

Eu achei que o método de ensino aplicado para a turma foi muito bom, fácil de entender e visualizar.

No começo achei bastante complicado, mas na hora da prova eu estava confiante sobre meus pensamentos.

O sistema não tem mistério, pelo menos com duas premissas é um 
bom método.

Achei o método um pouco difícil no início, mas com o tempo fui entendendo. Achei muito interessante e divertido na prática.

Achei a aula de lógica interessante, mas complicada.

\section{CONSIDERAÇÕES FINAIS}

Ao final da unidade didática, os resultados positivos obtidos não consistiram apenas nas notas das provas, mas também na opinião anônima dos alunos, mostrando que essa experiência foi vantajosa à relação de ensino e aprendizagem das competências e conteúdos almejados.

Gostaria de concluir não apenas diagnosticando o sucesso desta aplicação do método diagramático para resolução de silogismos carrolliano como alternativa para o ensino de lógica no ensino médio, mas fomentando a busca por novas metodologias de ensino. Os livros didáticos são um recurso valioso em sala de aula, mas nenhum deles nos acorrenta como prisioneiros de seus métodos. Somos livres para buscar alternativas. Embora trilhar esse caminho traga desafios, também guarda tesouros esperando para serem encontrados.

\section{REFERÊNCIAS}

BRASIL. Ministério da Educação. Comitê Gestor da Base Nacional Comum Curricular e Reforma do Ensino Médio. Base Nacional Comum Curricular: para o Ensino Médio. Brasília: Ministério da Educação, Secretaria da Educação Básica, 2018.97 p.

BRASIL. Ministério da Educação. Secretaria de Educação Básica. Orientações curriculares para o ensino médio: volume 3. Brasília: Ministério da Educação, Secretaria da Educação Básica, 2006. $133 \mathrm{p}$.

CARROLL, L. The Game of Logic. London: MacMillan and Co., 1886. 128 p.

COLÉGIO NOSSA SENHORA MEDIANEIRA. Regimento: Educação Básica. Vinculado ao Sistema Estadual de Educação. Candelária, RS. 2017. 36 p.

COLL, C; MARTíN, E. Aprender Conteúdos \& Desenvolver Capacidades. Porto Alegre: Artmed, 2004.

ENGEL, P. Y a-t-il une vie après la dissertation? Côté-Philo: Le journal de l'enseignement de la philosophie, n. 9. out. 2006. p. 33-44.

GALLO, S. Metodologia do ensino de filosofia: uma didática para o Ensino Médio. Campinas, SP: Papirus, 2012.

LINDEMANN, J. L. O Jogo da Lógica de Lewis Carroll: Uma alternativa para o ensino médio. REFilo: Revista Digital de Ensino de Filosofia, v. 3; n 2. jul./dez. 2017. p. 165-179. Disponível em: <https:// periodicos.ufsm.br/refilo/article/view/28815>. Acesso em: 03 jan. 2019.

MONTOITO, R. Chá com Lewis Carroll: a matemática por trás da literatura. Jundiaí, Paco Editorial: $2011.211 \mathrm{p}$.

NEWTON, L. A. (Ed.). Medieval Commentaries on Aristotle's Categories. Boston: Brill, 2008.

PERRENOUD, P. MAGNE, B. C. Construir: as competências desde a escola. Porto Alegre: Artmed, 1999.

SECCO, G.D.; PUGLIESE, N. On how formal logic is presented to the Brazilian student: a critical 
analysis. In: Rutas didácticas y de investigación em lógica, argumentación y pensamiento crítico. México: Academia Mexicana de Lógica, 2016. p. 78-169. 